\title{
CARACTERIZAÇÃO AMBIENTAL DO RESERVATÓRIO DO PARQUE DAS ACÁCIAS - UBERABA (MG)
}

\author{
Marcos Fernandes Silva ${ }^{1}$
}

Diego de Souza Sardinha

Patrícia Diniz Martins ${ }^{3}$

Cristiano Poleto ${ }^{4}$

RESUMO: $O$ presente trabalho teve como finalidade a caracterização ambiental e a analise das concentrações de oxigênio dissolvido $(\mathrm{mg} / \mathrm{L})$ no reservatório do Parque das Acácias - Uberaba (MG). Para a caracterização ambiental, foi realizado um levantamento bibliográfico, bem como, visitas aos órgãos públicos. O levantamento de campo foi feito utilizando equipamento GPS (Global Positioning System), sendo, também aplicado o Índice de Análise Ambiental Simplificado (IAAS). As amostragens de oxigênio dissolvido

\footnotetext{
${ }^{1}$ Graduando em Engenharia Ambiental - Universidade Federal do Triângulo Mineiro (UFTM). markimfsv@hotmail.com

${ }^{2}$ Engenheiro Ambiental pelo Instituto de Ensino Superior COC de Ribeirão Preto (SP). É mestre e doutor em Geologia Regional pelo Instituto de Geociências e Ciências Exatas da Universidade Estadual Paulista Júlio de Mesquita Filho de Rio Claro (SP). Atualmente é Professor Adjunto do Instituto de Ciência e Tecnologia (ICT) da Universidade Federal de Alfenas (Unifal) - Campus avançado de Poços de Caldas (MG). diegosardinha@yahoo.com.br

${ }^{3}$ Engenheira Ambiental - Ma Recursos Hídricos Energéticos e Ambientais -UFTM: Instituto de Ciências Tecnológicas e Exatas (ICTE). patricia_ambiental@hotmail.com

${ }^{4}$ Engenheiro Civil - PhD em Recursos Hídricos e Meio Ambiente - Universidade Federal do Rio Grande do Sul (UFRGS): Instituto de Pesquisas Hidráulicas (IPH). cristiano_poleto@hotmail.com
} 
foram realizadas durante Agosto/2011 a Fevereiro/2012, caracterizando as variações extremas em um ano hidrológico. Nos pontos P1, P2 e P3 (reservatório R-1) as concentrações de oxigênio dissolvido se mostraram satisfatórias. O ponto P4 (reservatório R-2), as concentrações de oxigênio dissolvido foram baixas durante o estudo provavelmente pelo acumulo de sedimentos e matéria orgânica, que entrando em decomposição consome o oxigênio dissolvido tornando área com características pantanosas. Pelo IAAS a área encontra-se pouco impactada.

Palavras-chave: Qualidade da água. Sustentabilidade. Enchentes

\section{INTRODUÇÃO}

O uso adequado dos recursos naturais, principalmente dos recursos hídricos, vem sendo considerado de grande importância, pois a água está presente em toda a atmosfera, litosfera e biosfera (corpos d'água, ar, solo, subsolo e seres vivos) e desempenha importantíssima função em quase todas as atividades humanas, econômicas, sociais, culturais e até religiosas (FELDMANN, 1992). Os usos múltiplos da água incluem, além da irrigação e da utilização doméstica, a navegação, a recreação e o turismo. A diversificação dos usos múltiplos da água, o despejo de efluentes líquidos e resíduos sólidos em rios, lagos e represas aliadas a destruição de áreas alagadas e matas galeria tem produzido uma sistemática deterioração da qualidade da água.

A introdução de matéria orgânica em um corpo d'água resulta, indiretamente, no consumo de oxigênio dissolvido. Tal se deve aos processos de estabilização da matéria orgânica realizadas pelas bactérias decompositoras, as quais utilizam o oxigênio disponível no meio líquido para a sua respiração (von SPERLING, 1996). Neste sentido, o oxigênio dissolvido pode ser utilizado para a determinação do grau de poluição em corpos hídricos. 

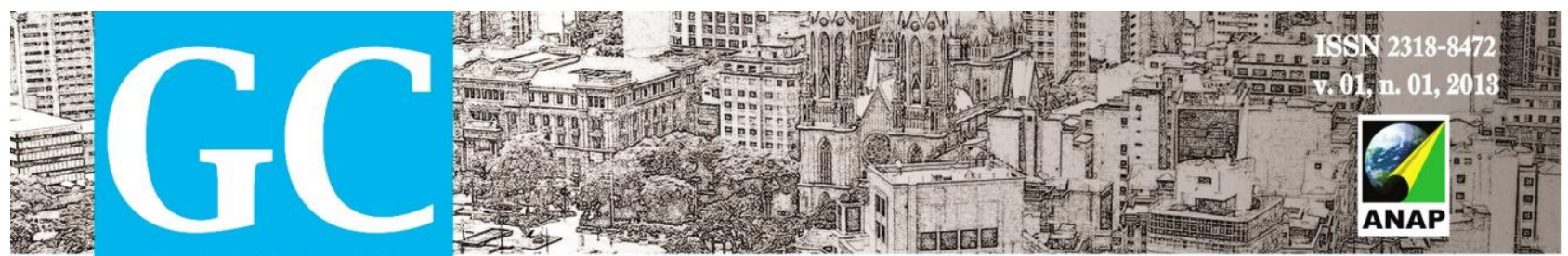

Revista Nacional de

Gerenciamento de Cidades

A construção de represas ou açudes nos rios tem uma grande importância como forma de regularização do regime de seus fluxos. Essa prática vem sendo utilizada desde os primórdios da civilização, mas só atingiu escala global nas últimas décadas (REBOLÇAS, et al., 2006). Atualmente, a qualidade de água de reservatórios é um tema central para o gerenciamento, estimulando o aprimoramento do monitoramento, a elaboração de um banco de dados, a aplicação de modelos ecológicos e matemáticos e a implantação de sistemas de suporte à decisão, para o controle efetivo da qualidade da água (STRASKRABA \& TUNDISI, 1999).

Assim, para o gerenciamento adequado de lagos, represas e áreas alagadas o primeiro passo é a caracterização ambiental visando elaborar alternativas para recuperação e conservação deste importante recurso. Neste sentido, o presente estudo teve como finalidade a caracterização ambiental do reservatório do Parque das Acácias, Uberaba (MG). Os resultados irão servir para o conhecimento das funções e processos do reservatório, visando à implantação futura de sistemas de modelagem ecológica que possibilitarão a busca de soluções qualitativas e quantitativas e a orientação para o desenvolvimento sustentado deste importante reservatório localizado no município de Uberaba (MG).

\section{OBJETIVO GERAL}

O presente trabalho tem como objetivo a caracterização ambiental do reservatório do Parque das Acácias, Uberaba (MG), e despertar o olhar critico sobre os impactos gerados no meio ambiente pelo homem. Os conhecimentos gerados neste trabalho podem fornecer subsídios necessários para a proposição de um monitoramento limnológico de quantidade e qualidade da água neste importante reservatório localizado na área urbana do município de Uberaba (MG). 


\section{OBJETIVOS ESPECÍFICOS}

Como objetivos específicos podem-se destacar:

a) Caracterização dos aspectos fisiográficos do reservatório do Parque das Acácias, Uberaba (MG), com a geração de banco de dados georreferenciado;

b) Quantificação espacial e temporal da concentração de oxigênio dissolvido (mg/L) nas águas do reservatório do Parque das Acácias no seu gradiente espacial e temporal.

\section{METODOLOGIA}

O reservatório do Parque das Acácias possui uma área de aproximadamente $70.000 \mathrm{~m}^{2}$ e situa-se entre os paralelos $19^{\circ} 44^{\prime} 51^{\prime \prime}$ e $19^{\circ} 45^{\prime} 11^{\prime \prime}$ de latitude $\mathrm{S}$ e meridianos $47^{\circ} 54^{\prime} 50^{\prime \prime}$ e $47^{\circ} 54^{\prime} 52^{\prime \prime}$ longitude W, na região oeste do Estado de Minas Gerais. O reservatório, localizado no bairro Parque do Mirante município de Uberaba, é alimentado pelas duas nascentes do Córrego Santa Rita (Figura 1). 

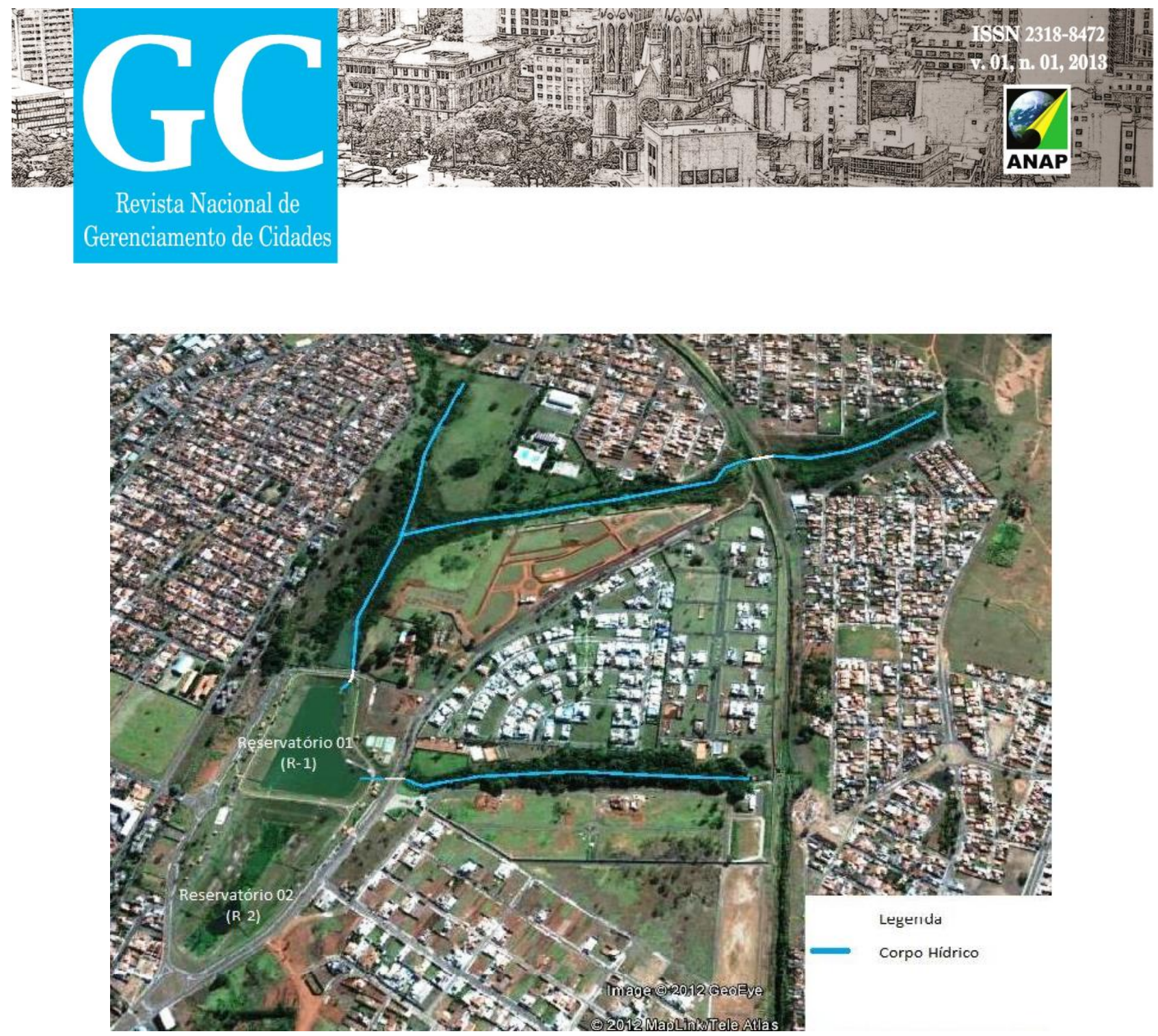

Figura 1 - Corpos Hídricos de Alimentação do Reservatório do Parque das Acácias.

\subsection{HISTÓRICO DO PARQUE DAS ACÁCIAS}

A Criação do Reservatório de Amortecimento de Cheias no entorno da bacia de Detenção, no Bairro Parque do Mirante, conhecido popularmente como "Piscinão" se originou como contrapartida da Prefeitura Municipal de Uberaba nas Obras do Projeto Água Viva. Atualmente o parque é revestido internamente por uma pista para caminhada e ciclovia e foram construídas pistas de skate e de bocha juntamente com quiosques providos de pias e bancadas além de sanitários, áreas de recreação, lanchonete, quadras poliesportivas, caramanchões e pista de cooper com piso táctil possibilitando aos deficientes visuais tranquilidade ao caminhar. 

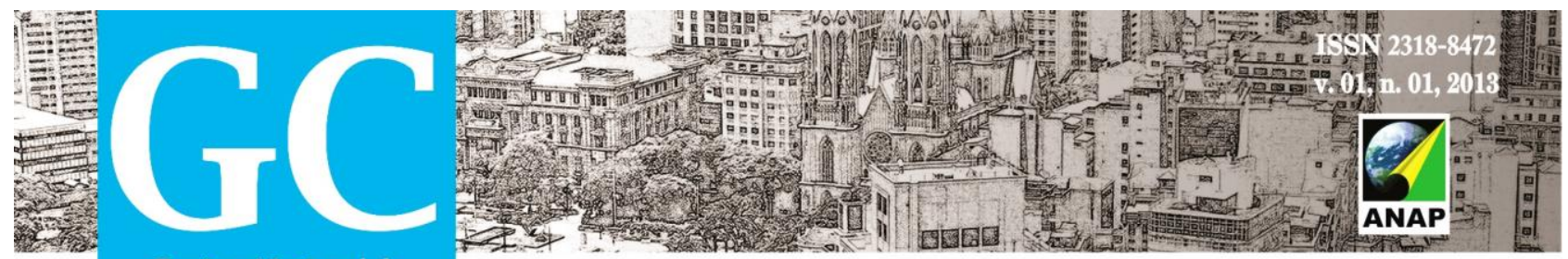

Revista Nacional de

Gerenciamento de Cidades

\subsection{PONTOS DE COLETA}

A Bacia de Amortecimento de Cheias ou Parque das Acácias é dotado de dois reservatórios, como mostra a Figura 2. O reservatório (R-1) controla as vazões provenientes da nascente do córrego Santa Rita, água oriunda dos condomínios residenciais em implantação ao redor do reservatório, entrando diretamente no reservatório através de escadas hidráulicas. O reservatório (R-2) controla as vazões provenientes da região a montante da Avenida Leopoldino de Oliveira, que entra no reservatório através de uma galeria em concreto implantada na Rua Nhadi J. Nassif. O reservatório R-2 recebe a vazão efluente do reservatório R-1 e recebe também as contribuições ao redor do reservatório.

O sistema de amortecimento de cheias do Parque das Acácias é do tipo II. Esse tipo de construção é caracterizado pelo escoamento da água pela parte superior do reservatório, o que influencia diretamente na temperatura da água e na quantidade nutrientes.

O segundo reservatório (R-2), se caracteriza, como uma área alagada do tipo pantanosa, muito comum em ecossistemas lênticos. Esse tipo de ecossistema é caracterizado pelas baixas concentrações de oxigênio dissolvido na água, devido a grande quantidade de matéria orgânica que se acumula no local.

Isso acontece devido ao fato de que as bactérias necessitam do oxigênio dissolvido na água para realizar a oxidação da matéria orgânica. Quando essa decomposição ocorre, isso gera um ambiente onde se dificulta a sobrevivência de seres aeróbicos. Os pontos de coleta foram distribuídos buscando observar as modificações no curso de água devido ao represamento (Figura 2). O ponto (P1) está localizado na entrada da nascente principal do córrego Santa Rita, o rio foi retificado e entra no reservatório por meio de uma galeria. O ponto (P2), localizado na entrada da nascente secundaria do córrego Santa Rita, também retificado, entra por meio de galerias fluviais que deságuam em um leito 


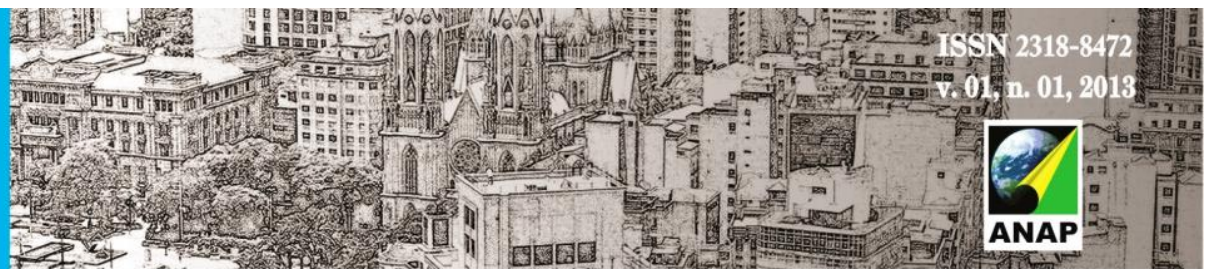

Revista Nacional de

Gerenciamento de Cidades

canalizado, desembocando no reservatório por meio de uma escada hidráulica. O ponto (P3) situa-se no exutório do reservatório (R-1) trata-se de uma galeria que desemboca na área alagada por meio de uma escada hidráulica. Por fim, o ponto (P4) localiza-se no reservatório dois (R-2), após a área alagada.
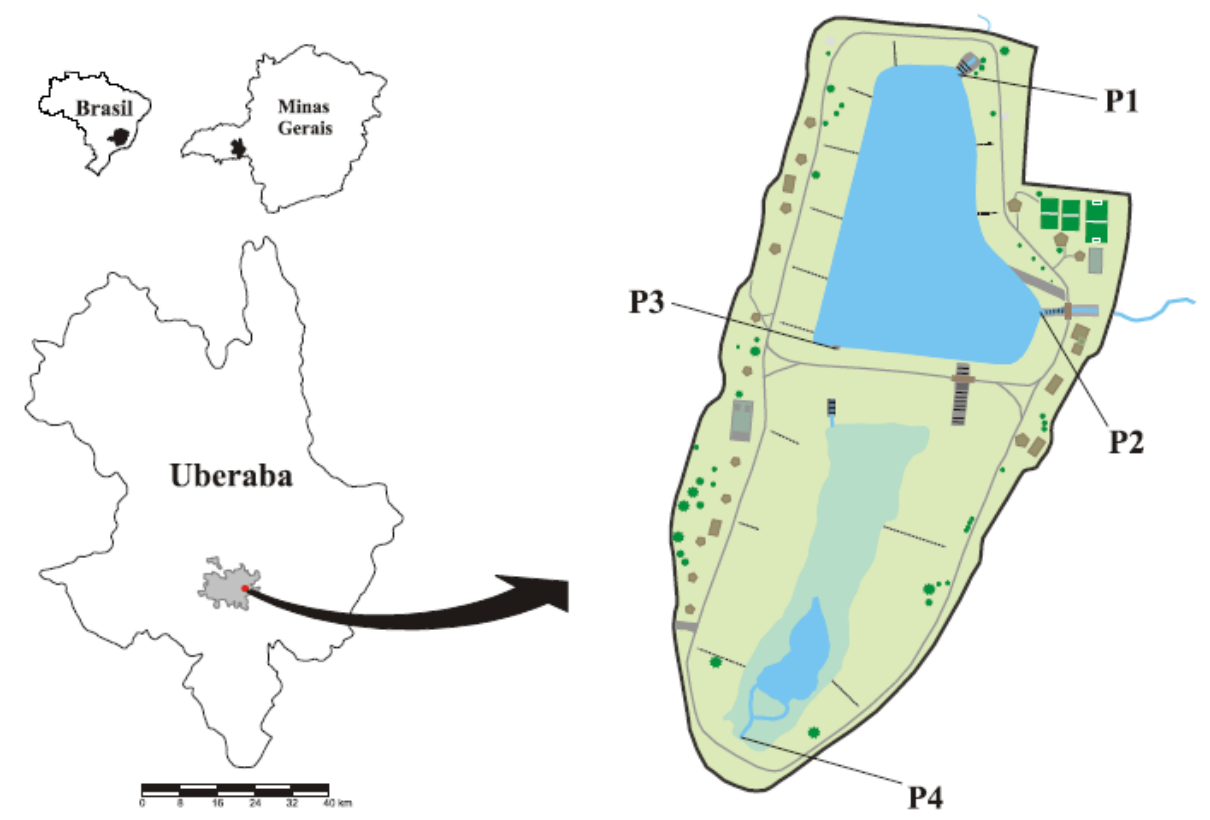

\section{LEGENDA}

Limite do Parque das

Acácias

Curso d'água e

reservatório

Área alagada

Gramado

\begin{tabular}{|l|l}
\hline Pontos de coleta \\
\hline
\end{tabular}

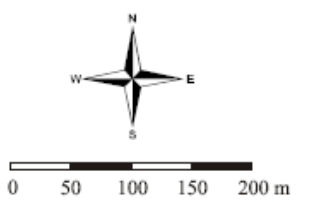

Figura 2 - Localização e distribuição espacial dos pontos de coleta.

\subsection{USO E OCUPAÇÃO DO SOLO}

Desde as eras mais antigas, sabe-se que grandes civilizações se desenvolveram ao lado de recursos hídricos que seriam capazes de subsidiar seu desenvolvimento, fornecendo água para consumo e produção de alimentos. A cidade de Uberaba, localizada na Bacia Hidrográfica do Rio Uberaba, apresentou ocupação entorno desse importante rio, que abastece a cidade até os dias atuais. A ocupação no entorno do Parque das Acácias, também é um fator recente, no qual se tem a implantação de 


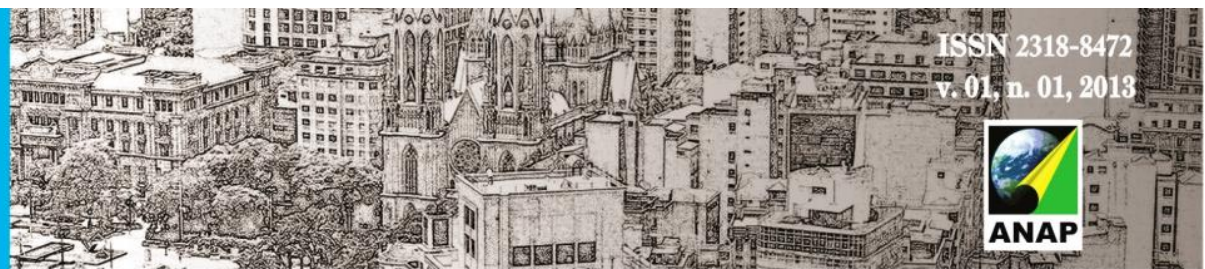

Revista Nacional de

Gerenciamento de Cidades

inúmeros condomínios e bairros residenciais. Por se tratar de uma área considerada calma, grande valor econômico foi agregado no entorno do parque, caracterizando uma população de nível social mais elevado.

Grandes obras de pavimentação, construção de galerias pluviais, impermeabilização dos solos dentro dos condomínios por meio da construção de calçadas, também presentes no entorno do parque influenciam diretamente na capacidade de absorção de água da chuva pelo solo, sendo ela transportada diretamente para os reservatórios do Parque.

Junto as nascentes do Córrego Santa Rita, ainda prevalecem à presença de sítios e chácaras, mas que devido a grande expansão que ocorre no local, futuramente podem não existir, passando a predominar uma realidade que se convive no centro da cidade (canalização do leito natural do rio, o que influencia diretamente na velocidade de escoamento das águas, ocasionando enchentes).

Para melhor caracterização dos pontos para coleta, foi aplicado o Índice de Análise Ambiental Simplificada (IAAS), para averiguação das condições ambientais do local, de acordo com o modelo da Tabela 1 que contem as características e seus respectivos pesos.

Tabela 1 - Modelo da ficha de campo para Análise Ambiental Simplificada com os devidos pesos. 


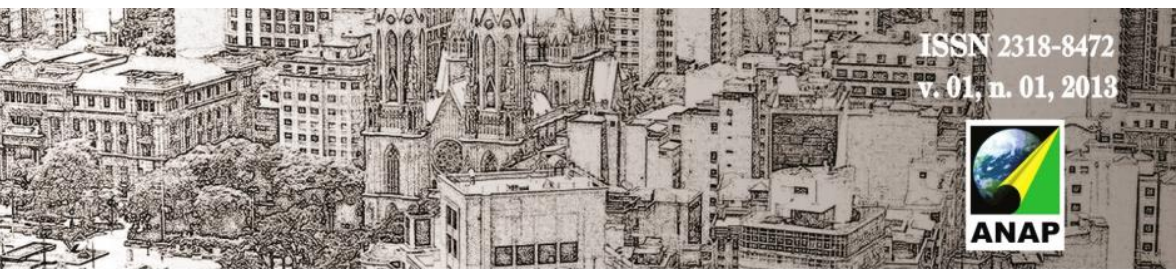

Revista Nacional de

Gerenciamento de Cidades

\begin{tabular}{|c|c|c|c|}
\hline Indicadores biofisicos & Peso & Indicadores biofisicos & Peso \\
\hline Erosão no entorno & & Odor & \\
\hline Boçoroca & 0 & Muito forte & 0 \\
\hline Sulco & 1 & Forte & 1 \\
\hline Ravina & 2 & Fraco & 2 \\
\hline Sem erosão & 3 & Ausente & 3 \\
\hline Impactos na vegetação & & Óleos & \\
\hline Muito impacto (sem vegetação) & 0 & Muito alto & 0 \\
\hline Médio impacto (- $50 \%$ da vegetação) & 1 & Alto & 1 \\
\hline Pouco impacto ( $+50 \%$ da vegetação) & 2 & Baixo & 2 \\
\hline Sem impacto & 3 & Ausente & 3 \\
\hline Fauna no entorno & & Espumas & \\
\hline Ausência de animais nativos & 0 & Muito alta & 0 \\
\hline Pouca presença animais nativos & 1 & Alta & 1 \\
\hline Moderada presença animais nativos & 2 & Baixa & 2 \\
\hline Grande presença de animais nativos & 3 & Ausente & 3 \\
\hline Saneamento & & Algas / clorofila & \\
\hline Fossa e/ou esgoto & 0 & Muito alto & 0 \\
\hline Dejetos ou urina & 1 & Alto & 1 \\
\hline Entulhos lixo & 2 & Baixo & 2 \\
\hline Ausente & 3 & Ausente & 3 \\
\hline Lixo no entorno do recurso hídrico & & Larvas e vermes vermelhos & \\
\hline Muito lixo & 0 & Muito alta & 0 \\
\hline Pouco lixo & 1 & Alta & 1 \\
\hline Lixo em latões & 2 & Baixa & 2 \\
\hline Sem lixo & 3 & Ausente & 3 \\
\hline \multicolumn{4}{|l|}{ Turbidez da água } \\
\hline Muito alta & 0 & & \\
\hline Alta & 1 & & \\
\hline Baixa & 2 & & \\
\hline Ausente & 3 & & \\
\hline
\end{tabular}

De acordo com a somatória dos pesos de cada local analisado, os mesmos podem ser classificados de acordo com o grau de impacto no qual se encontra. Essa classificação foi assim determinada de acordo com a Tabela 2, onde o maior valor possível no somatório dos pesos é 33 e este se caracteriza por representar a melhor classificação da área. 


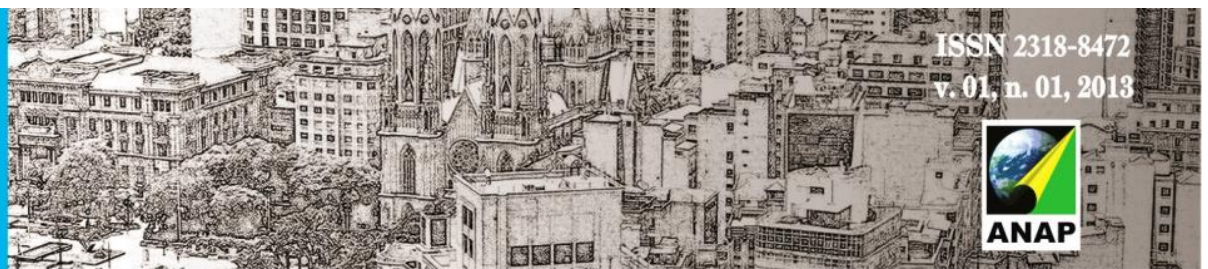

Revista Nacional de

Gerenciamento de Cidades

Tabela 2- Intervalos de valores e Classificação do Impacto dos indicadores Biofísicos.

\begin{tabular}{cc}
\hline Intervalo de valores & Classificação dos impactos \\
\hline $33-25$ & Pouco impacto \\
$24-17$ & Impacto moderado \\
$16-10$ & Impacto alto \\
$10-0$ & Impacto preocupante \\
\hline
\end{tabular}

Para a realização do projeto no Parque das Acácias, foram selecionados quatro pontos para coleta de água para análise de oxigênio dissolvido. A Localização de cada ponto está descrito na Tabela 3 e na Figura 2.

Tabela 3 - Coordenadas geográficas dos Pontos de Coleta

\begin{tabular}{cccc}
\hline Pontos & \multicolumn{2}{c}{ Coordenadas geográficas } & Referencias \\
& $\boldsymbol{S}$ & $\boldsymbol{W}$ & Córrego Santa Rita, afluente principal do \\
P1 & $19^{\circ} 44^{\prime} 86^{\prime}$, & $47^{\circ} 54^{\prime} 75^{\prime}$, & reservatório. \\
& & & \\
P2 & $19^{\circ} 44^{\prime} 97^{\prime}$, & $47^{\circ} 54^{\prime} 70^{\prime}$, & Córrego Santa Rita, afluente esquerdo do \\
P3 & $19^{\circ} 44^{\prime} 59^{\prime}$, & $47^{\circ} 54^{\prime} 49^{\prime}$, & reservatório. \\
P4 & $19^{\circ} 45^{\prime} 10^{\prime}$, & $47^{\circ} 54^{\prime} 52^{\prime}$, & Exultório do Reservatório 01. \\
\hline
\end{tabular}

A concentração de oxigênio dissolvido ( $\mathrm{mg} / \mathrm{L}$ ) nas águas superficiais, foi caracterizada através de equipamento com eletrodos de leitura direta no próprio local de amostragem. Para isso, foi utilizado o medidor portátil de oxigênio dissolvido HQ 40d multi da Hach (método eletrométrico). 


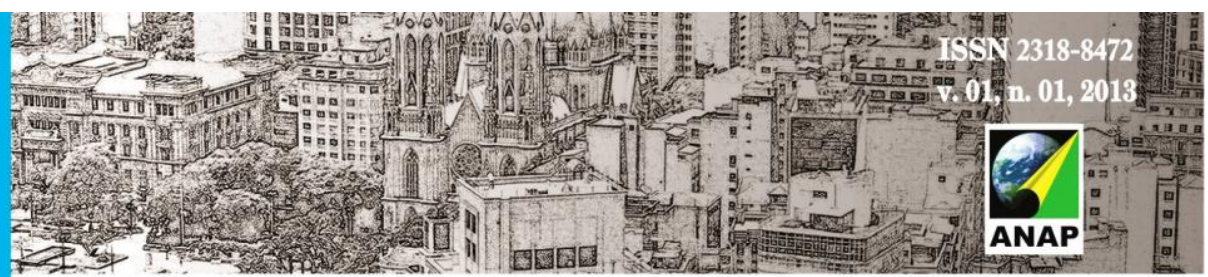

Revista Nacional de

Gerenciamento de Cidades

\section{RESULTADOS}

Os resultados obtidos foram divididos entre aqueles provenientes do Índice de Análise Ambiental Simplificado - IAAS e aquele resultante da análise de oxigênio dissolvido aferido em campo. Entretanto os mesmos estão relacionados entre si, já que as características do local influenciam nos parâmetros medidos em campo.

\section{1 ÍNDICE DE ANÁLISE AMBIENTAL SIMPLIFICADO - IAAS}

De acordo com o modelo aplicado em campo e os intervalos adotados, os resultados obtidos para cada ponto e sua respectiva classificação em relação ao impacto, se encontram descritos na Tabela 4. Vale ressaltar que esses resultados demonstram a visão do pesquisador, já que os pesos atribuídos em todas as características equivalem à visão pessoal e pode distinguir de outro pesquisador.

Tabela 4 - Resultados do IAAS aplicado nos quatro pontos avaliados no Reservatório do Parque das Acácias. 
Revista Nacional de

Gerenciamento de Cidades

\begin{tabular}{|c|c|c|c|c|c|c|}
\hline & $\begin{array}{c}\text { Turbidez } \\
\text { da água }\end{array}$ & $\begin{array}{l}\text { Lixo no } \\
\text { recurso }\end{array}$ & $\begin{array}{l}\text { Impacto do } \\
\text { Saneamento }\end{array}$ & $\begin{array}{l}\text { Fauna do } \\
\text { entorno }\end{array}$ & $\begin{array}{c}\text { Impactos } \\
\text { na } \\
\text { vegetação }\end{array}$ & $\begin{array}{l}\text { Erosão no } \\
\text { entorno }\end{array}$ \\
\hline ฐั้ & 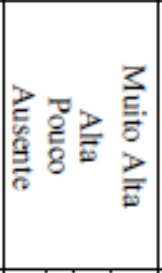 & 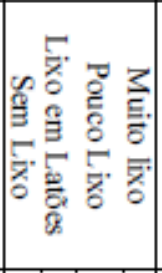 & 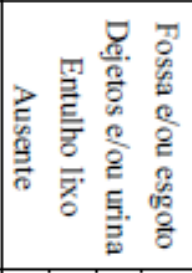 & 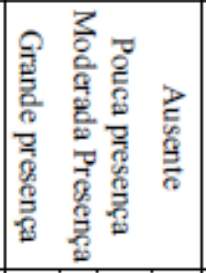 & 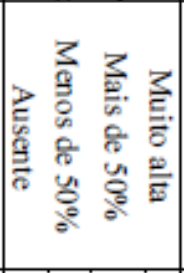 & 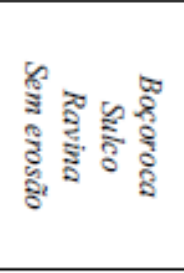 \\
\hline$P 1$ & $\mathrm{x}$ & $\mathrm{x}$ & $\mathrm{x}$ & $\mathrm{x}$ & $\mathrm{x}$ & $\mathrm{x}$ \\
\hline$P 2$ & $\mathrm{X}$ & $\mathrm{x}$ & $\mathrm{X}$ & $\mathrm{x}$ & $\mathrm{x}$ & $\mathrm{x}$ \\
\hline$P 3$ & $\mathrm{X}$ & $\mathrm{x}$ & $\mathrm{X}$ & $\mathrm{x}$ & $\mathrm{x}$ & $\mathrm{x}$ \\
\hline \multirow[t]{3}{*}{ P4 } & $\mathrm{x}$ & $\mathrm{x}$ & $\mathrm{x}$ & $\mathrm{x}$ & $\mathrm{x}$ & $\mathrm{x}$ \\
\hline & Odor & Óleos & Espumas & $\begin{array}{l}\text { Algas i } \\
\text { Clorofila }\end{array}$ & $\begin{array}{l}\text { Larvase } \\
\text { Vermes }\end{array}$ & I.A.A.S. \\
\hline & 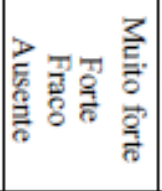 & 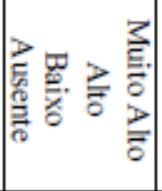 & 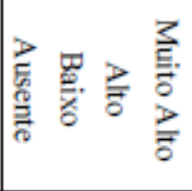 & 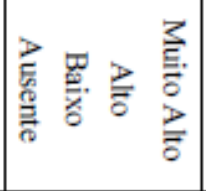 & 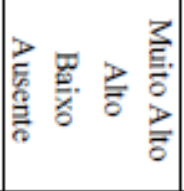 & $\begin{array}{c}\text { Tipo de } \\
\text { Impacto } \\
\text { Associado }\end{array}$ \\
\hline$P 1$ & $\mathrm{x}$ & $\mathrm{x}$ & $\mathrm{x}$ & $\mathrm{x}$ & $\mathrm{x}$ & $\begin{array}{c}\text { Pouco } \\
\text { Impacto(25) }\end{array}$ \\
\hline$P 2$ & $\mathrm{x}$ & $\mathrm{x}$ & $\mathrm{x}$ & $\mathrm{x}$ & $\mathrm{x}$ & $\begin{array}{c}\text { Pouco } \\
\text { Impacto(27) }\end{array}$ \\
\hline P3 & $\mathrm{x}$ & $\mathrm{x}$ & $\mathrm{x}$ & $\mathrm{x}$ & $\mathrm{x}$ & $\begin{array}{c}\text { Pouco } \\
\text { Impacto(27) }\end{array}$ \\
\hline P4 & $\mathrm{x}$ & $\mathrm{x}$ & $\mathrm{x}$ & $\mathrm{x}$ & $\mathrm{x}$ & $\begin{array}{c}\text { Pouco } \\
\text { Impacto(27) }\end{array}$ \\
\hline
\end{tabular}

Pela analise feita através do método aplicado, conclui-se que todos os pontos de coleta estão sofrendo pouco impacto ambiental no momento. Vale resaltar que o Índice de Avaliação Ambiental Simplificado (IAAS) pode obter variações, pois leva em consideração a visão do pesquisador. 


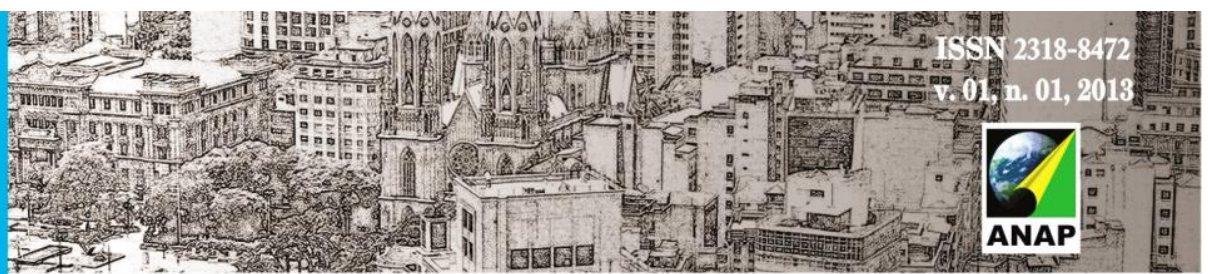

Revista Nacional de

Gerenciamento de Cidades

No ponto 1, o maior valor de oxigênio dissolvido foi $6,97 \mathrm{mg} / \mathrm{L}$ em Agosto e o menor de $4,37 \mathrm{mg} / \mathrm{L}$ em Setembro, indicando que a água que entra no reservatório por meio da galeria do Ponto P1 é adequada para o desenvolvimento de vida aquática como pode ser visualizado na Figura 3.

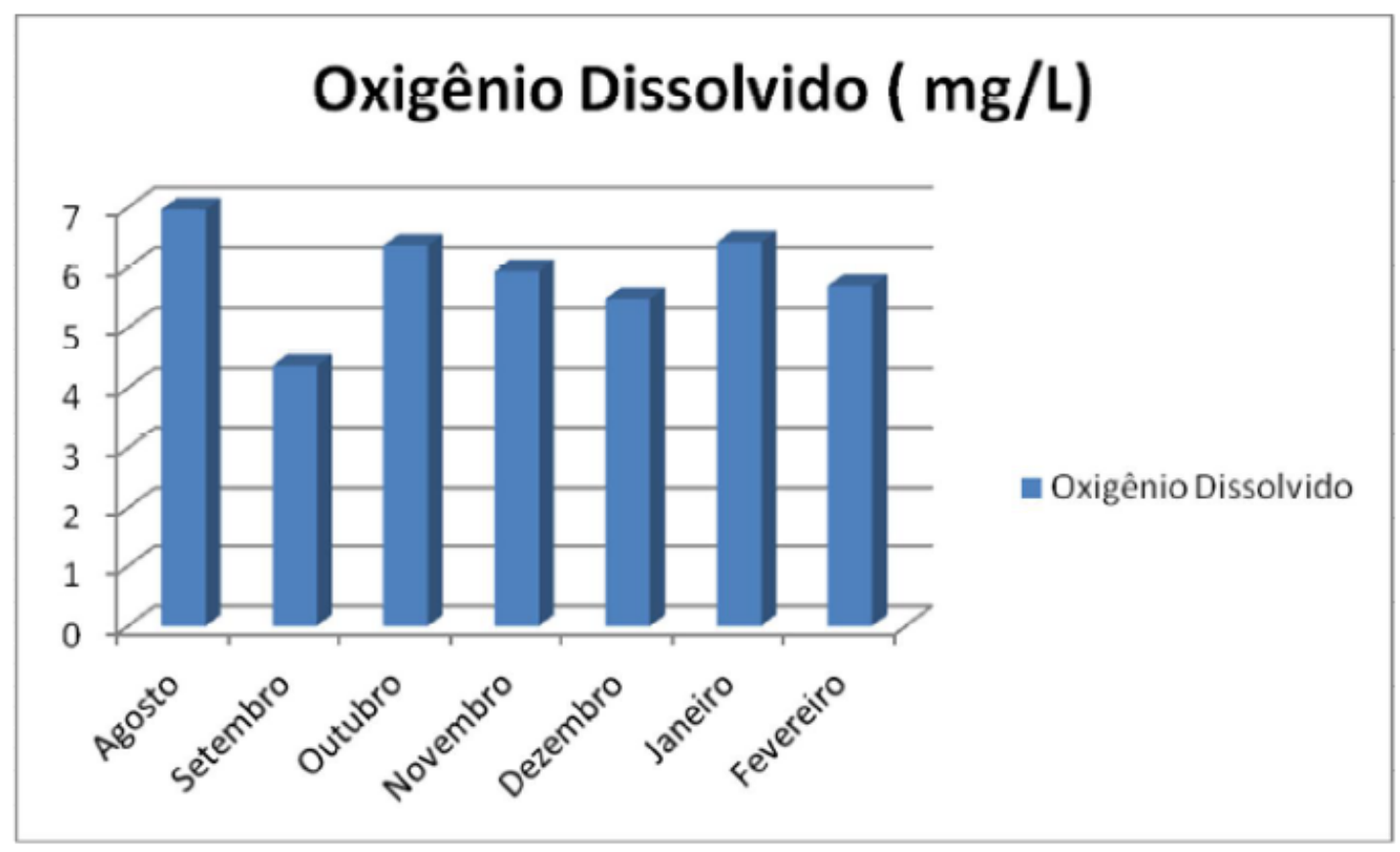

Figura 3 - Oxigênio Dissolvido analisados no ponto P1.

O ponto P2 é caracterizado por ser o afluente secundário do reservatório do Parque das Acácias (Piscinão), e aflui ao reservatório por meio de uma galeria fluvial seguido de leito canalizado e escada hidráulica, os valores de oxigênio dissolvido podem ser visualizados na Figura 4. 


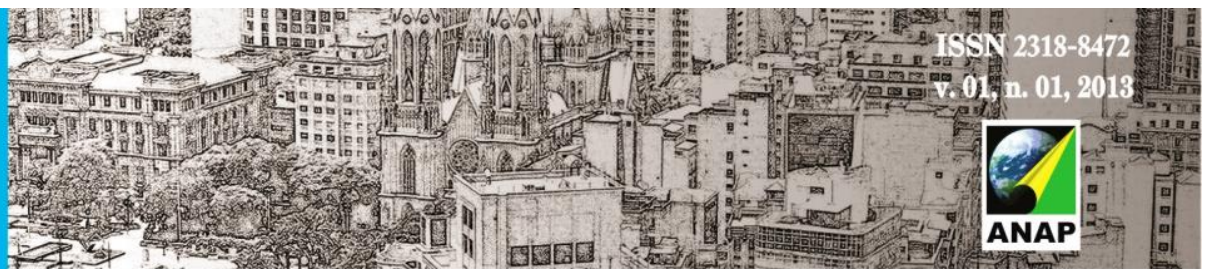

Revista Nacional de

Gerenciamento de Cidades

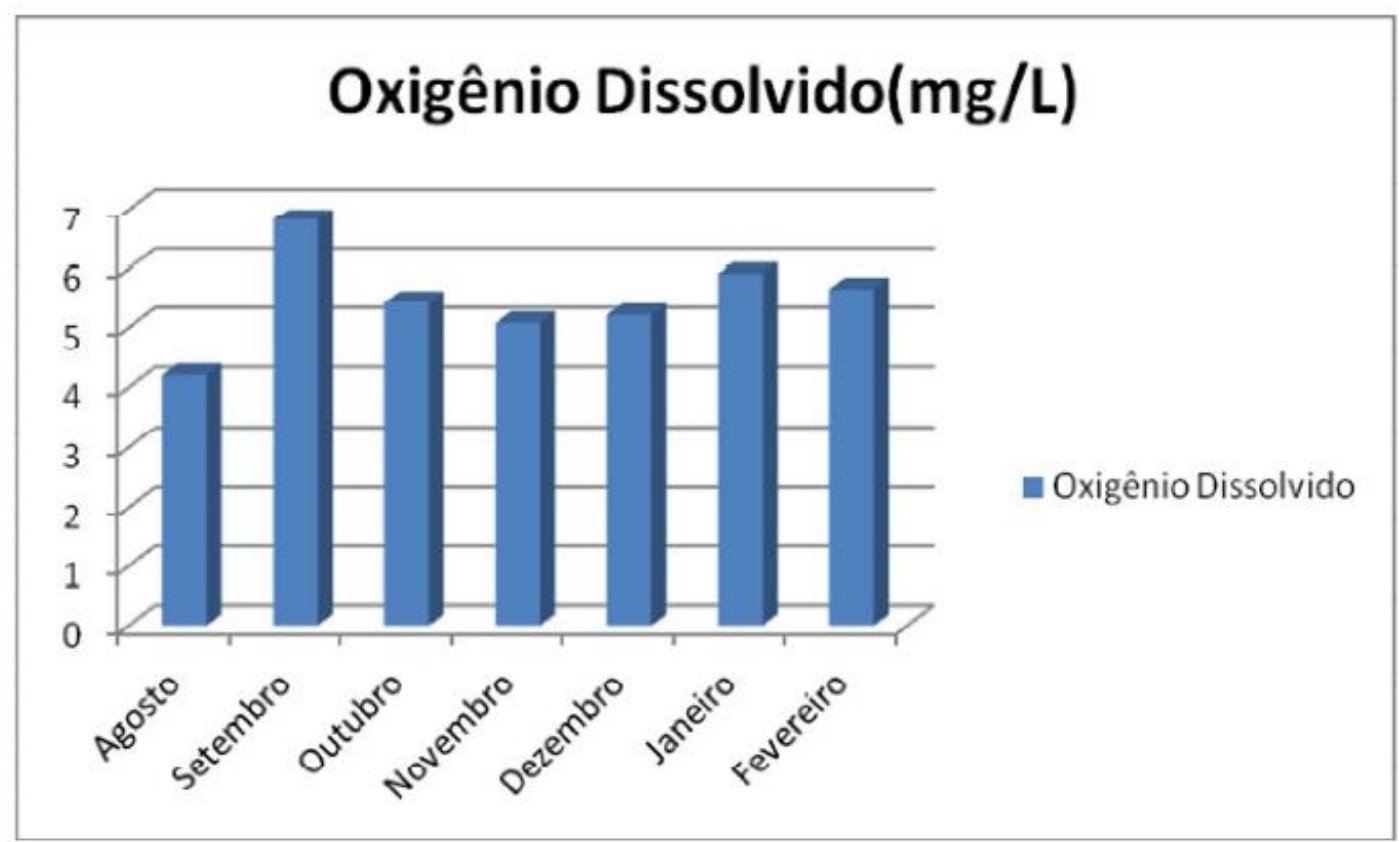

Figura 4 - Oxigênio dissolvido no ponto P2.

O ponto P3 é caracterizado por ser o exutório do reservatório do Parque das Acácias, onde as águas drenam por galerias de leito canalizado e uma escada hidráulica, local aonde as amostras eram analisadas. $O$ menor valor de oxigênio dissolvido foi observado em novembro e o maior em Agosto (Figura 5). 


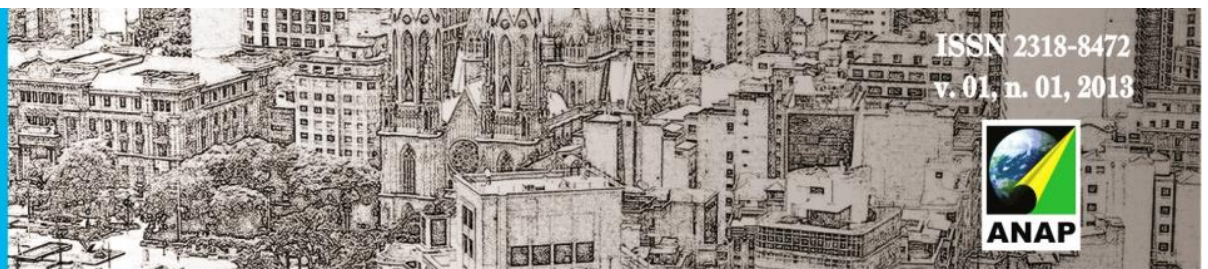

Revista Nacional de

Gerenciamento de Cidades

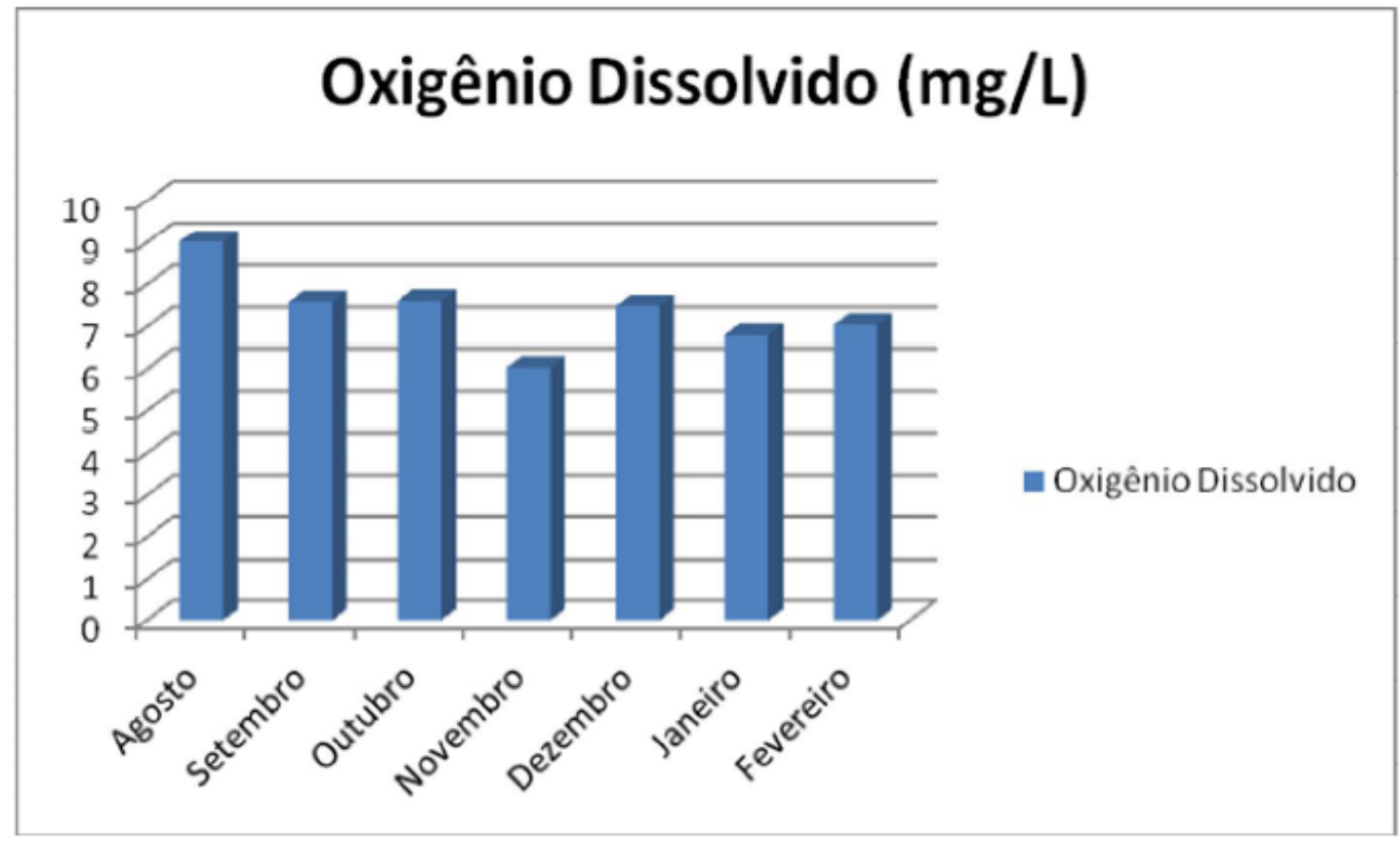

Figura 5 - Oxigênio dissolvido no ponto P3.

O trajeto pelo o qual o leito do rio percorre pode influenciar na quantidade de oxigênio dissolvido, pelo fato de que o processo de agitação mecânica tende a aumentar a solubilização do mesmo na água.

O ponto P4 é caracterizado por estar após área alagada do reservatório dois (R-2) no Parque das Acácias (Piscinão), pode-se observar na Figura 6 que os valores de oxigênio dissolvido estão abaixo da média dos demais pontos. 


\section{Oxigênio Dissolvido ( $\mathrm{mg} / \mathrm{L}$ )}

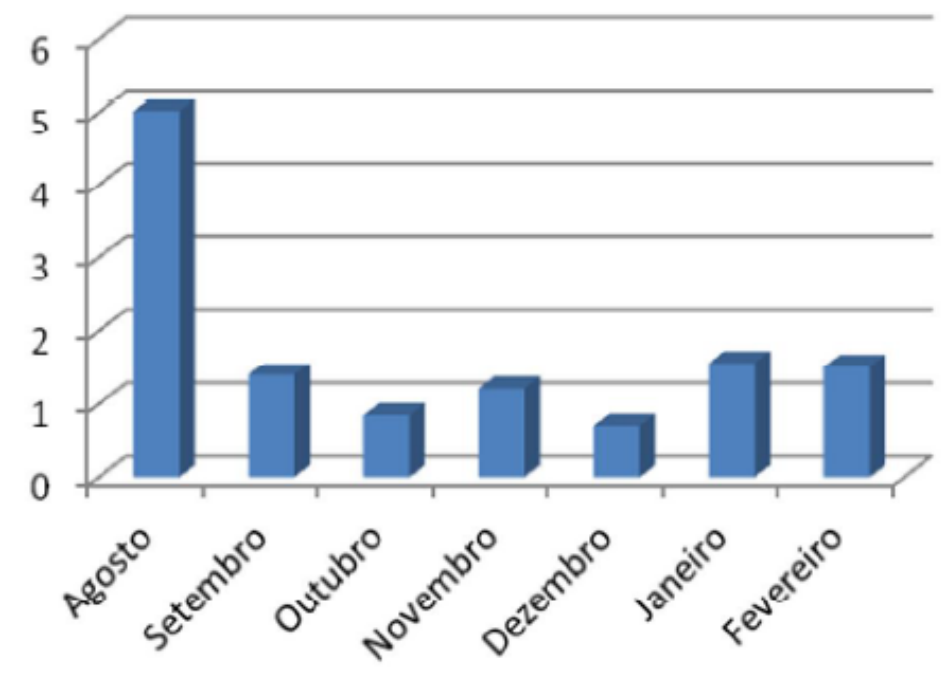

n Oxigênio Dissolvido

Figura 6 - Oxigênio dissolvido no ponto P4.

Os pontos P1 e P2 apresentam, quanto aos parâmetros analisados, comportamento semelhante. Os resultados do Índice de Analise Ambiental Simplificado IAAS apontam boa qualidade das águas que entram no reservatório. Fato confirmado pelas analises de oxigênio dissolvido analisadas nestes dois pontos.

Quando a água entra no reservatório R-1 e fica armazenada por determinado tempo, fica sujeita a varias condições que podem vim a afetar a sua qualidade. $\mathrm{O}$ parâmetro analisado mostra que, as águas se encontram em bom estado, aquelas intermediárias, aptas a proporcionar o desenvolvimento de espécies aquáticas no reservatório $\mathrm{R}-1$, ou seja, altas concentraçõesde oxigênio dissolvido (OD).

O ponto P4 apresenta maior degradação ambiental, quando comparado com os resultados do IAAS e da qualidade da água dos demais pontos (P1, P2 e P3) analisados. Altas concentrações de matéria orgânica, observadas em campo, tornam a água turva. $O$ 
reservatório R-2 esta localizado no nível mais baixo do Complexo de Amortecimento de Cheias e funciona como um reservatório emergencial, caso chuvas de grande intensidade venham ocorrer no local. Por esse motivo o reservatório R-2 possui uma área sempre alagada (pântano). Isto reflete diretamente nas amostras analisadas, com valores de oxigênio dissolvido baixos.

\section{CONSIDERAÇÕES FINAIS}

A abordagem metodológica empregada neste trabalho teve como finalidade analisar a qualidade das águas dos reservatórios do Sistema de Amortecimento de Cheias do Parque das Acácias. Os resultados obtidos através dos parâmetros analisados permitiram avaliar as condições ambientais dos recursos hídricos estudados.

Assim de modo geral, as águas do Parque das Acácias estão em estado razoavelmente aceitáveis dentro dos parâmetros de classificação da qualidade da água. O problema encontrado seria o grande acumulo de matéria orgânica que acaba afetando as concentrações de oxigênio dissolvido no local. Isto demonstra um contraste da qualidade da água entre o reservatório R-1 e o reservatório R-2. Neste sentido, o monitoramento limnilógico trata-se uma ferramenta importante para avaliação de recursos hídricos. Pesquisas realizadas em reservatórios avaliam se as águas são aptas para especificas finalidades e quando o estudo é feito de forma periódica e constante, gera um banco de dados dos parâmetros analisados, que podem servir de base para outros estudos. 


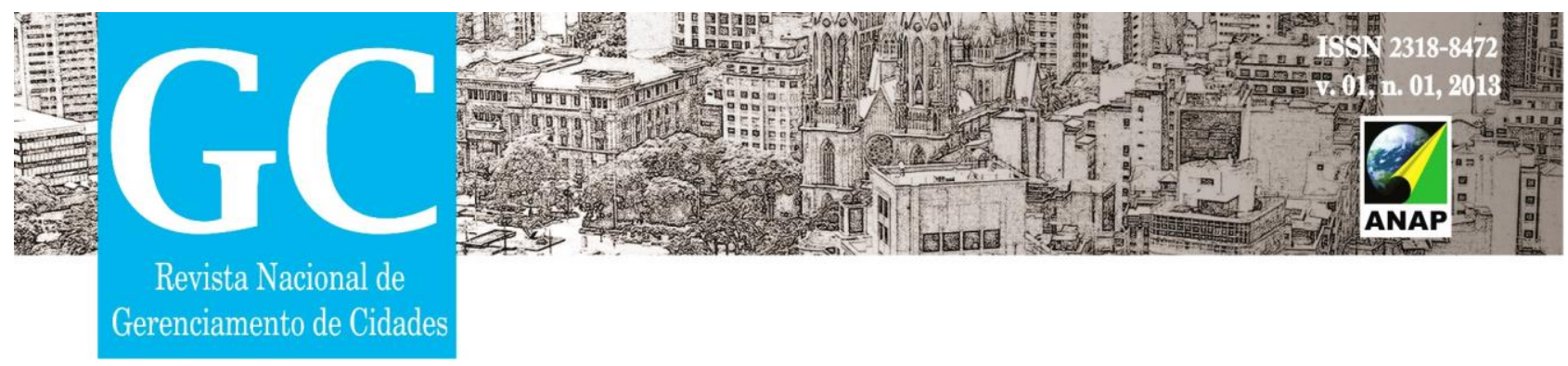

\section{REFERÊNCIAS}

FELDMANN, F. Guia da Ecologia: para entender e viver melhor a relação homem natureza. São Paulo, Editora Abril, 62 p., 1992.

REBOUÇAS A.C. Água doce no mundo e no Brasil. In: Águas doces no Brasil, Rebouças A.C.; Braga B.J.; Tundisi J.G. São Paulo, $3^{\circ}$ ed., Escrituras, 748 p., 2006.

STRASKRABA M.; TUNDISI J.G. Reservoir Water Quality Management: Guidelines of Lake Management. Kusatsu, Japan: International Lake Environmental Committee, v.9, 227p., 1999.

VON SPERLING, M. Introdução à qualidade das águas e ao tratamento de esgotos. $2^{\circ}$ ed. UFMG, Belo Horizonte, 243p., 1996 